\title{
Impacts of Photovoltaic Distributed Generation Location and Size on Distribution Power System Network
}

\author{
N. Md. Saad ${ }^{1}$, M. Z. Sujod ${ }^{2}$, Lee Hui Ming ${ }^{3}$, M. F. Abas ${ }^{4}$, M. S. Jadin ${ }^{5}$, M. R. Ishak ${ }^{6}$, \\ N. R. H. Abdullah ${ }^{7}$ \\ Sustainable Energy \& Power Electronics Research Laboratory, Faculty of Electrical and Electronic Engineering, \\ Universiti Malaysia Pahang, Malaysia
}

\begin{tabular}{l} 
Article Info \\
\hline Article history: \\
Received Dec 21, 2017 \\
Revised Jan 22, 2018 \\
Accepted Feb 7, 2018 \\
\hline
\end{tabular}

\section{Keyword:}

Photovoltaic DG

Load flow analysis

Fault analysis

Voltage stability

Power losses

\begin{abstract}
As the rapid development of photovoltaic (PV) technology in recent years with the growth of electricity demand, integration of photovoltaic distributed generation (PVDG) to the distribution system is emerging to fulfil the demand. There are benefits and drawbacks to the distribution system due to the penetration of PVDG. This paper discussed and investigated the impacts of PVDG location and size on distribution power systems. The medium voltage distribution network is connected to the grid with the load being supplied by PVDG. Load flow and short circuit calculation are analyzed by using DigSILENT Power Factory Software. Comparisons have been made between the typical distribution system and the distribution system with the penetration of PVDG. Impacts in which PVDG location and size integrates with distribution system are investigated with the results given from the load flow and short circuit analysis. The results indicate positive impacts on the system interconnected with PVDG such as improving voltage profile, reducing power losses, releasing transmission and distribution grid capacity. It also shows that optimal locations and sizes of DGs are needed to minimize the system's power losses. On the other hand, it shows that PVDG interconnection to the system can cause reverse power flow at improper DG size and location and increases short circuit level.
\end{abstract}

Copyright $@ 2018$ Institute of Advanced Engineering and Science. All rights reserved.

Corresponding Author:

N. Md. Saad, M. Z. Sujod

Department of Electrical and Electronic Engineering,

Universiti Malaysia Pahang,

26600 Pekan, Pahang Darul Makmur, Malaysia

Email: norhafidzah@ump.edu.my,zahim@ump.edu.my

\section{INTRODUCTION}

Energy shortage and environmental problems have become the main problem that we faced today. The power demand that keeps growing has increased electrical energy production to almost its maximum capacity [1], [2]. This leads to the increasing usage of the natural gas and coal which are the two main natural resources for electricity production in Malaysia [3]. As we know, these two resources are exhaustible which will be used up in one day. Besides, combustion of the fuels and gas will emit unfavourable gases which cause pollution to the environment and hence lead to the health problem. Various developments and utilizations of renewable energy have been researched and implemented in order to solve this problem. Distributed generation (DG) has become a trend in power system which can help in support the power demand and overcome the congested transmission lines [1]. It is connected near to the loads which reduce transmission loss but the load still needs to rely on both power grid and DG. Renewable resources such as the wind and photovoltaic are usually used as the base for the distributed generation. Various renewable energy (RE) programs had been developed and launched in Malaysia such as Suria 1000, Feed in Tariff (FiT) and so on in order to encourage and increase public awareness on green technologies [3]-[6]. 
Solar energy is ideal green technology for sustainable development. However, it can be categorized as the intermittent type of DG which it cannot be precisely controlled or predictable [7]. There may be restrictions for PVDG as it restricts from weather conditions and geographic features; at the same time, the cost of land to install PVDG can be costly [8]. Hence, there will be technical issues and impacts come out when integrating PVDG to the distribution system network [9].

There are numerous advantages of implementing PVDG which includes increased reliability and the losses are reduced. Besides that, the integration of PVDG to the distribution system could improve the voltage profile so that the system can bear high loading situations. Other advantages are transmission and/or distribution stress is reduced. Finally, DG technologies cause lower rate of pollution to the environment with higher efficiency such as combined heat and power and micro-turbines. While for renewable energy based DG such as PVDG, it is zero emission which will not pollute the environment [10].

The technology is also having its drawbacks. High penetration level of PVDG may cause reverse power flow at feeder and substation transformer level. A unidirectional protection system in the distribution system may be affected. Thus, it may affect voltages and loading limits of some transformers. Besides that, high penetration level of DG may cause voltage fluctuations due to the integrated uncertainty sources. For PVDG, the fluctuation solar source will cause over or under voltage. Other drawbacks are high penetration of DG can lead to more harmonic propagation. It may increase the losses and shorten the equipment's life time. The Total Harmonic Distortion (THD) will be increased as the interaction among the power electronics interfaced equipment such as the Distribution Energy Storage (DES) with the capacitor bank. Finally, the power system common unidirectional flow patterns will be affected as the DG flows in bidirectional. Thus, a suitable protection scheme is needed [11]-[12].

In this paper, the interconnection of photovoltaic based distributed generation with power systems grid is discussed. The influences in terms of benefits and impacts for the integration of PVDG with the distribution system network are investigated by comparing the result of analysis for normal distribution system and distribution system with PVDG. The location and size of PVDG are also examined. The impacts of PVDG location and size is identified by determination factor using DigSILENT Power Factory software.

\section{RESEARCH METHODOLOGY}

\subsection{Modeling of Distribution Sytem}

There are two distribution networks used in this study by constructing in DigSilent Power Factory software which are modified $11 \mathrm{kV}$ and $33 \mathrm{kV}$ distribution networks based on Malaysian distribution system. They consist of network that operates at medium (MV) and low (LV) voltage levels which are $33 \mathrm{kV}, 11 \mathrm{kV}$ and $433 \mathrm{~V}$. Both networks are connected to the grid and one of the loads is supplied by a PVDG. Figure 1 and Figure 2 show the $11 \mathrm{kV} \& 33 \mathrm{kV}$ distribution networks. The grid at nominal voltage $132 \mathrm{kV}$ is stepped down to $11 \mathrm{kV}$ and $33 \mathrm{kV}$ using transformers. Both of the $11 \mathrm{kV}$ and $33 \mathrm{kV}$ are arranged in a single-bus singlebreaker scheme which the two busses are connected through a bus-coupler breaker. For the $11 \mathrm{kV}$ distribution network, there are 2 incoming feeders from the power transformer and 7 outgoing feeders with total 21 loads and 2 motor loads. Whereas, $33 \mathrm{kV}$ side, there are 2 incoming feeders and 4 outgoing feeders with 5 loads. Switches and circuit breakers are added in the distribution system network to add reliability which power can still be supplied from other substation if the respective substation breaks down. Each $11 / 0433 \mathrm{kV}$ and $33 / 11 \mathrm{kV}$ substation are comprised of transformer and loads. For the dotted line, it shows the connection of unity power factor PVDG to the load. PVDG is chosen to be used because Malaysia is located near to the equator of the earth which benefits in getting abundant of sunlight. Various size of PVDG is used in this project in order to analyze its impacts to the distribution networks.

\subsection{Analysis Description}

To study the impacts of PVDG location and size to the distribution system network, various assessments had been done. This section briefly summarizes the various aspects that had been considered from the results of load flow and short circuit analysis. There are two cases which are the normal $11 \mathrm{kV} \&$ $33 \mathrm{kV}$ distribution network without implementing PVDG and $11 \mathrm{kV} \& 33 \mathrm{kV}$ distribution network with PVDG. Furthermore, peak and normal loads for both distribution networks had been analyzed to see the penetration effects of the PVDG. For overall assessments, the power factor of PVDG is 1 which is unity. 


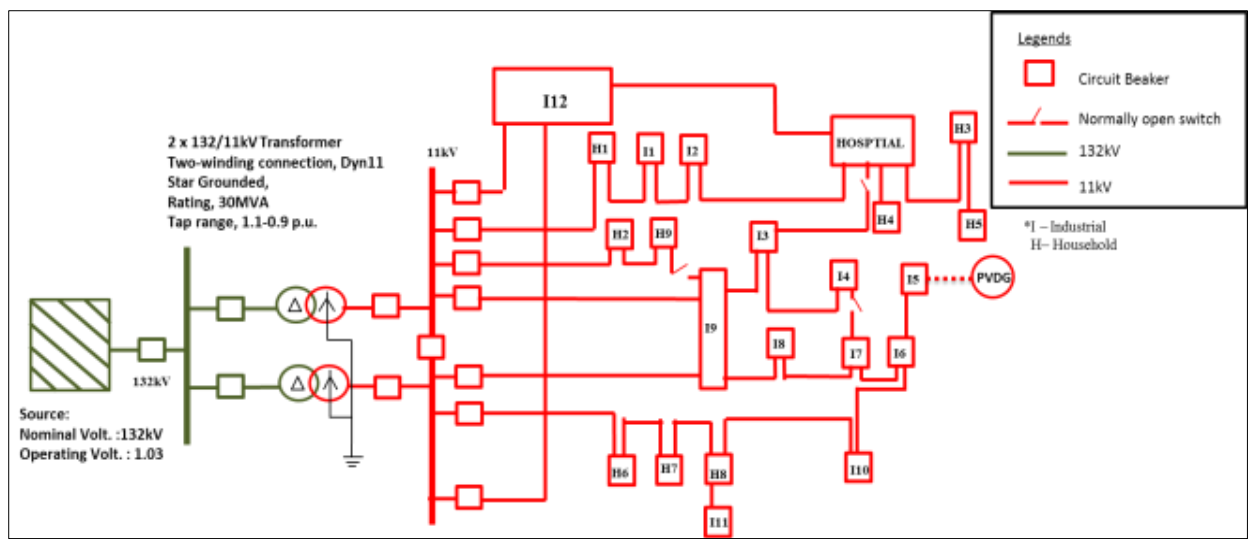

Figure 1. 11kV Distribution System Network

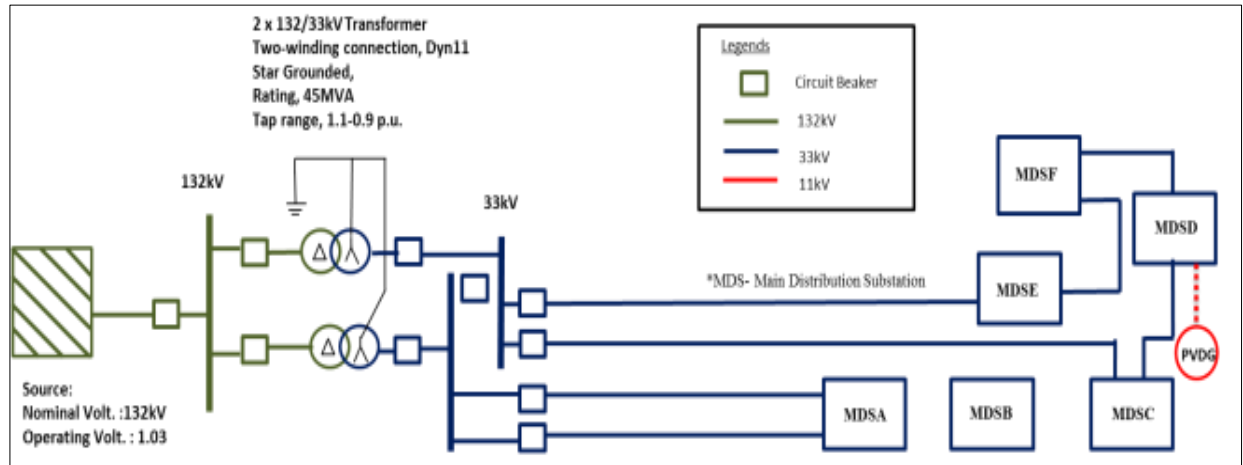

Figure 2. 33kV Distribution System Network

\subsubsection{Power Losses}

One of the impacts for PVDG are the losses in the system. There are two aspects discussed in this section which are the location of PVDG and its size. Both of the characteristics will affect on the power losses for the overall system and the assessments have been done with load flow analysis. Locating PVDG in an optimum location is important as it will increase reliability and stability of the system with reduced losses. There are several types of methods such as numerical, deterministic, sensitivity index, heuristic and stochastic method have been developed in order to find optimum location and sizing of DG in power system network. Hueristic algorithm such as genetic algorithm (GA), particle swarm optimization (PSO) and many more have been developed to optimize DG operation for power loss reduction, line load reduction, voltage profile improvement at optimal DG investment cost [13]-[21]. In this project, it is done by locating each peak load with 0.1MW and 1MW PVDG respectively and check for its power losses. The optimal location for PVDG with lowest losses will be the best location for locating the PVDG for both $11 \mathrm{kV} \& 33 \mathrm{kV}$ distribution networks. Besides, the size for the PVDG is also an important criterion that needs to be analyzed as the high penetration level of PVDG will give an adverse effect on the system losses. Both $11 \mathrm{kV} \& 33 \mathrm{kV}$ distribution networks have different size of PVDG as the loads for both networks are not the same. For $33 \mathrm{kV}$, the sizes of PVDG to be analyzed are between 0 to $20 \mathrm{MW}$. For $11 \mathrm{kV}$, the sizes of PVDG to be analyzed are between 0 to $5 \mathrm{MW}$.

\subsubsection{Main Grid}

The amount of main grid's power generation is analyzed in order to check the impacts once integrating with PVDG. Load flow analysis is done in order to check for the main grid power generation and it is compared with distribution network without PVDG and networks with different sizes of PVDG for both $11 \mathrm{kV} \& 33 \mathrm{kV}$ distribution networks. 


\subsubsection{Voltage Profile}

Power flow analysis is performed in order to study the voltage profile of the overall system for both $11 \mathrm{kV} \& 33 \mathrm{kV}$ distribution networks after they are connected to the PVDG. With this approach, it can detect the occurrence of reverse power flow once the voltage per unit is out of statutory limit which is $\pm 5 \%$ of the normal operating voltage or the voltage p.u is less than 0.95 p.u or more than 1.05 p.u.

\subsubsection{Short-circuit Current}

Fault involves a short circuit between any phases to the ground or between phases are in very high current flows. It needs to be interrupted by protection devices before causing damage to the system [22]. Impacts on the short circuit current for the feeders once integrating with PVDG are analyzed by short-circuit analysis. Results for short circuit analysis for each of the distribution networks are compared between typical network and network with a different size of PVDG.

\section{RESULTS AND ANALYSIS}

\subsection{Impact of PVDG Location and Size on Power Losses}

Regarding on power losses, there is evidence that PVDG location and size has effect in both $33 \mathrm{kV}$ and $11 \mathrm{kV}$ distribution networks as DG injects active power to the network. Adding of the suitable capacity of the PVDG with respect to the feeder's capacity will show a positive effect on the losses. On the other hand, high penetration of PVDG to the distribution network will increase the power losses which cause the reverse power flow. Power losses $\left(I^{2} \mathrm{R}\right)$ are caused by the current flowing through the transmission line, transformer and distribution conductors. It can be decreased by reducing the resistance of the cable conductors or decreasing the load current flowing through them. The closer the distance of generation takes place to the loads, the lower the power losses as the voltage drop decreases at the same time the resistance of the conductors decreases. Besides, reduction of current flowing through the distribution and transmission network when installing DG will reduce the power losses too. The DG not only decreases active power but reactive power as it is like installing capacitor bank which aids in supply reactive power. In this project, unity power factor PVDG is used. Hence, there is no reactive power supply to the system but with the decrease in active power, reactive power will reduce too. The location of installing PVDG and its size are crucial in affecting the power losses.

In locations where PVDG have installed, there is a significant reduction in power losses. The least power losses occur in the location will be chosen as the optimum location in implementing PVDG. Every peak load locations had been tried to install the PVDG with two different sizes which are $0.1 \mathrm{MW}$ and $1 \mathrm{MW}$ in order to choose the optimum location by using load flow analysis. The total peak losses for the network without implementing PVDG are $1.27 \mathrm{MW}$ for $33 \mathrm{kV}$ and $0.43 \mathrm{MW}$ for $11 \mathrm{kV}$. For $11 \mathrm{kV}$, load $\mathrm{I} 5$ seems to be the perfect location whereas MDSD will be the best location for $33 \mathrm{kV}$ as shown in Figure 3 and Figure 4. It can be seen that different locations with different load sizes and power flow will get a different level of benefits from the PVDG. For the rest of the locations, there are decreased in power losses but in comparison with MDSD and $\mathrm{I} 5$ for $33 \mathrm{kV}$ and $11 \mathrm{kV}$ distribution networks, they just seem to be lower and these make them less attractive.

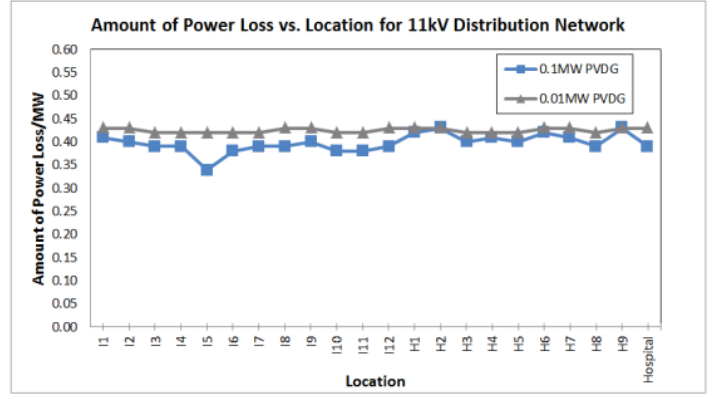

Figure 3. Power Loss vs. Location of Implementing PVDG for $11 \mathrm{kV}$ Distribution Network

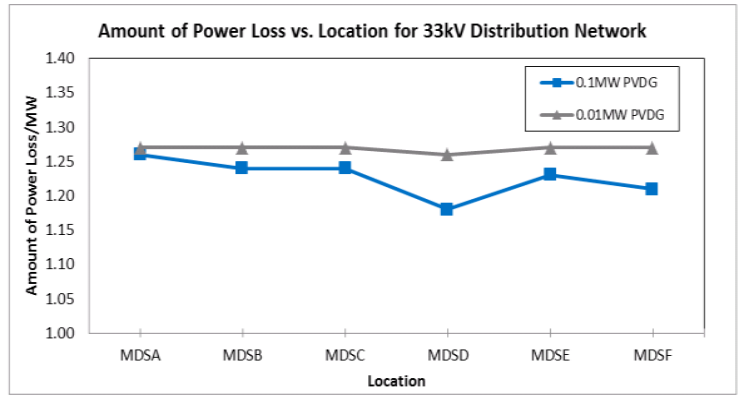

Figure 4. Power Loss vs. Location of Implementing PVDG for 33kV Distribution Network 
As the size of the PVDG increases, the active and reactive power loss decreases first until to certain limit of size for PVDG and then increases. Figure 5 and Figure 7 shows the amount of active power loss with respect to the size of PVDG while Figure 6 and Figure 8 show the amount of reactive power loss with respect to the size of PVDG. The active power losses are more obvious and vigorous when the size of the PVDG increases as compared to reactive power losses. This is due to the unity power factor of PVDG. However, the high penetration of PVDG will cause an adverse effect to the distribution network for both $11 \mathrm{kV}$ and $33 \mathrm{kV}$. When the amount of PVDG is small, it reduces the power losses as the net transmission power of feeder line is less. When the PVDG capacity exceeds the capacity of the load, the active and reactive power losses increase as the PVDG will feed power to the other lines like what the main grid does. From the results given, it seems that PVDG below $3 \mathrm{MW}$ is suitable for $11 \mathrm{kV}$ peak load distribution network whereas PVDG which less than $10 \mathrm{MW}$ are suitable for the $33 \mathrm{kV}$ peak load distribution network. In other words, high penetration up to $140 \%$ of PVDG which is higher than the peak load I5 for $11 \mathrm{kV}$ distribution network shows an adverse effect on the power losses. For $33 \mathrm{kV}$ peak load, $108 \%$ of PVDG penetration shows the increase in power losses. For normal load, 2MW PVDG is suitable for $11 \mathrm{kV}$ distribution network while 9MW PVDG is suitable for the $33 \mathrm{kV}$ distribution network. Hence, it shows that the lower the load, the lower the size is suitable for PVDG to integrate with the distribution networks.

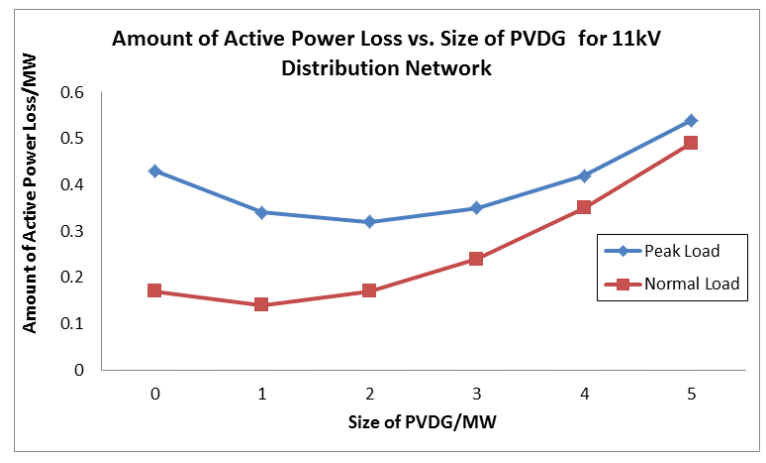

Figure 5. Active Power Loss vs. Size of PVDG for $11 \mathrm{kV}$ Distribution Network

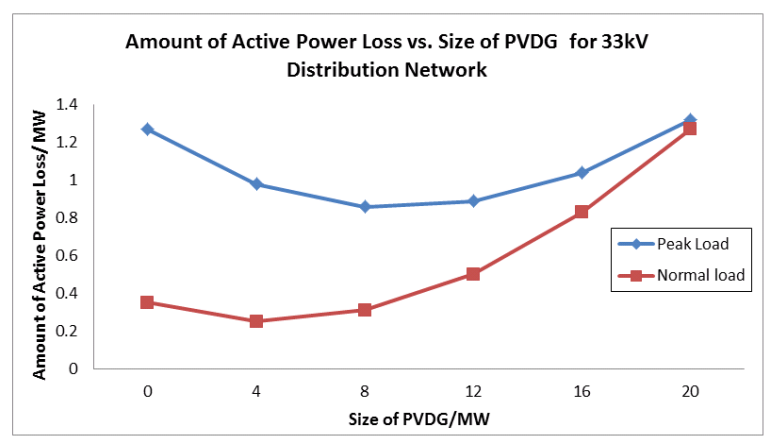

Figure 7. Active Power Loss vs. Size of PVDG for $33 \mathrm{kV}$ Distribution Network

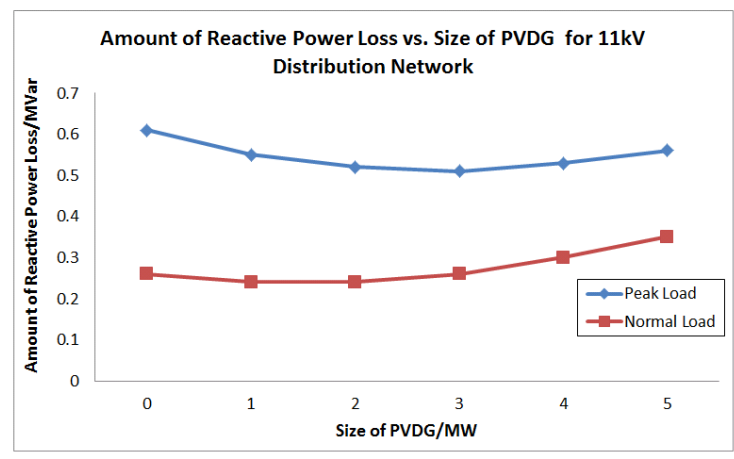

Figure 6. Reactive Power Loss vs. Size of PVDG for $11 \mathrm{kV}$ Distribution Network

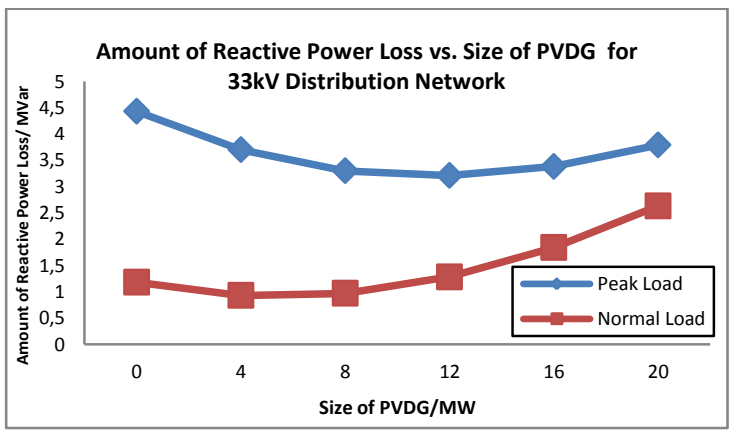

Figure 8. Reactive Power Loss vs. Size of PVDG for $33 \mathrm{kV}$ Distribution Network

\subsection{Impact of PVDG Size on Main Grid's Power Generation}

As shown in Figure 9 and Figure 11, the bigger the size of PVDG for both $11 \mathrm{kV} \& 33 \mathrm{kV}$ distribution networks, the less the main grid active power generation capacity. DG can aid in providing power generation to the loads and is considered as a fast solution in boosting power generation with its short construction times. For Figure 10 and Figure 12, they show that the bigger the size of PVDG, the less the main grid reactive power generation capacity until they reach a certain point and increase back again. This is due to the PVDG aids in generating power but when the penetration of PVDG is high, the main grid has to 
generate more reactive power to support the system as it is a unity power factor DG. The increasing power losses when the bigger size of PVDG integrated to the system also cause the reactive power to change as well. Besides, reactive power seems to be not much affecting by PVDG as compared to active power due to the unity power factor of PVDG too.

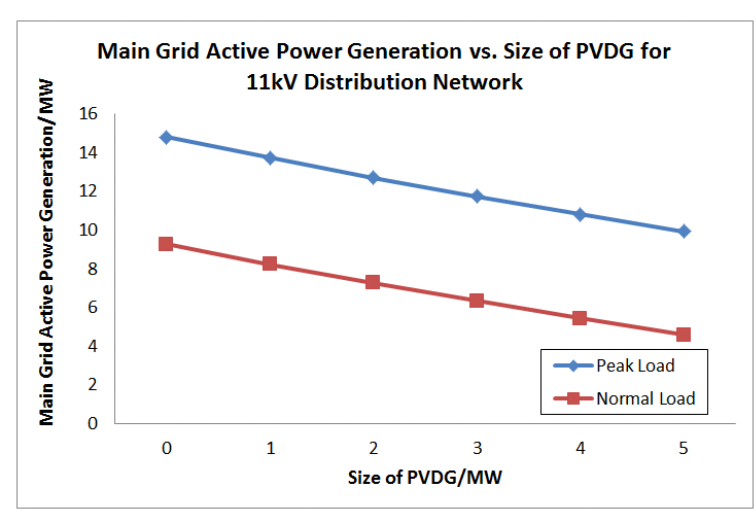

Figure 9. Main Grid Active Power Generation vs. Size of PVDG for $11 \mathrm{kV}$ Distribution Network

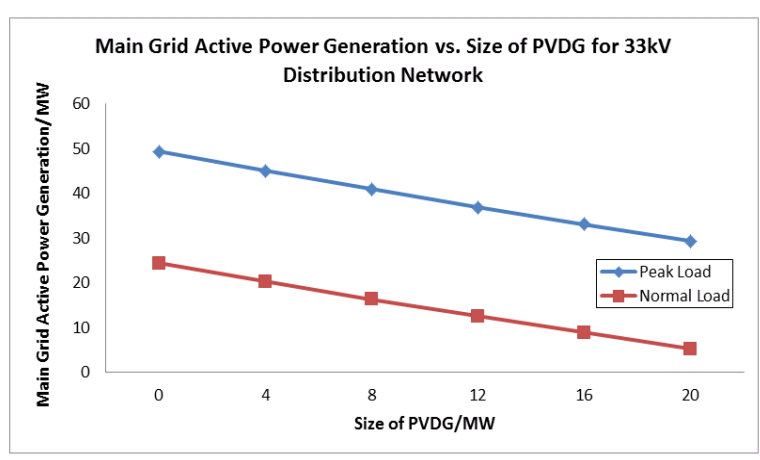

Figure 11. Main Grid Active Power Generation vs. Size of PVDG for $33 \mathrm{kV}$ Distribution Network

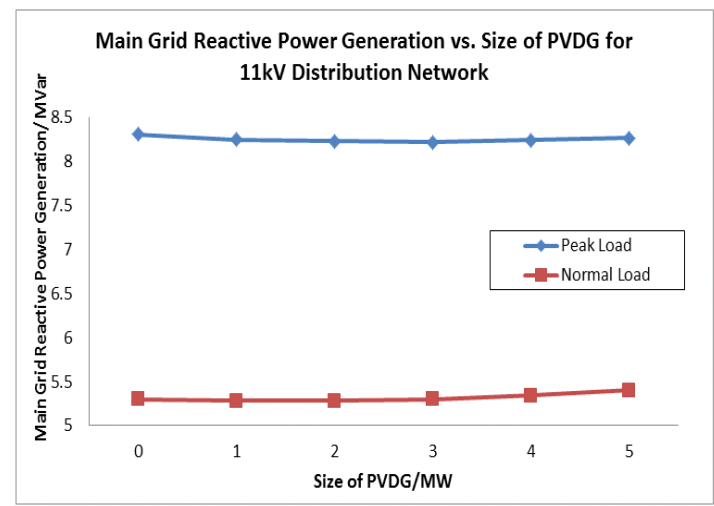

Figure 10. Main Grid Reactive Power Generation vs. Size of PVDG for $11 \mathrm{kV}$ Distribution Network

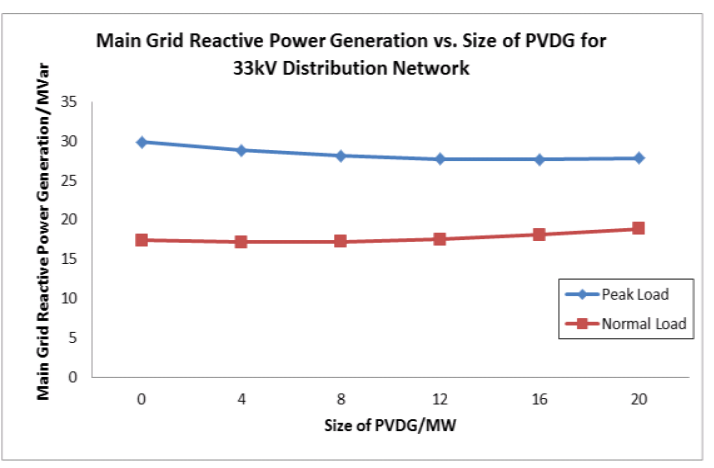

Figure 12. Main Grid Reactive Power Generation vs. Size of PVDG for 33kV Distribution Network

\subsection{Impact of PVDG Size on Voltage Profile}

From Figure 14 and Figure 16, they show that the higher the size of PVDG, the higher the voltage p.u until it over the statutory limits for busses that connected to PVDG. As the size of PVDG reaches 4MW for $11 \mathrm{kV}$ peak load distribution network, the voltage rises up over $1.05 \mathrm{p}$.u. This is due to the reversal of power flow as the high penetration of PVDG to the load. While for $33 \mathrm{kV}$ peak load, the reversal of power flow occurs at 17MW PVDG and 18MW PVDG for 33kV normal load. It also should be noted that the shunt capacitor connected in $33 \mathrm{kV}$ peak load aids in raising the voltage too. Thus, for $33 \mathrm{kV}$ normal load, the PVDG size is bigger for overvoltage to occur due to the absence of capacitor bank. The source voltage for $132 \mathrm{kV}$ for both networks are kept constant as power grid is the infinite bus supplied by $132 \mathrm{kV}$ grid station and PVDG will synchronize with it as shown in Figure 13 and 15. 


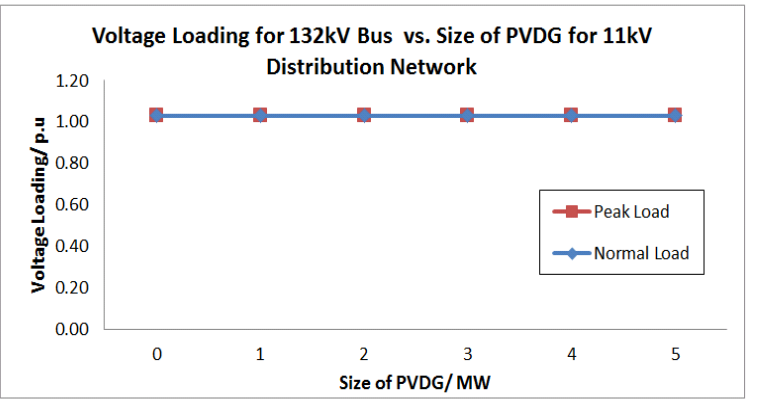

Figure 13. Voltage Loading for $132 \mathrm{kv}$ Bus vs. Size of PVDG for $11 \mathrm{kV}$ Distribution Network

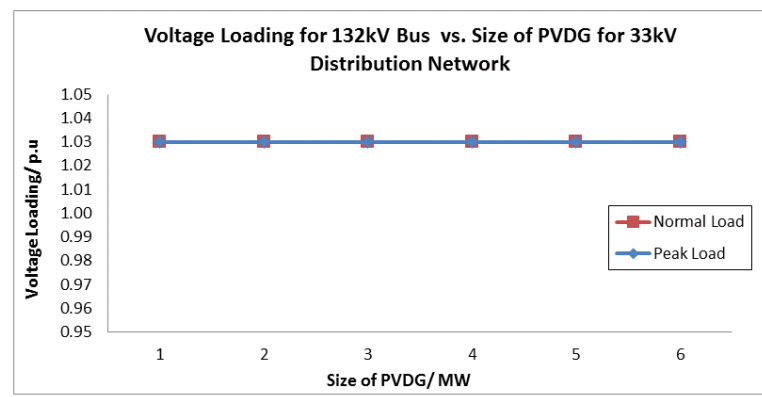

Figure 15. Voltage Loading for $132 \mathrm{kV}$ Bus vs. Size of PVDG for $33 \mathrm{kV}$ Distribution Network

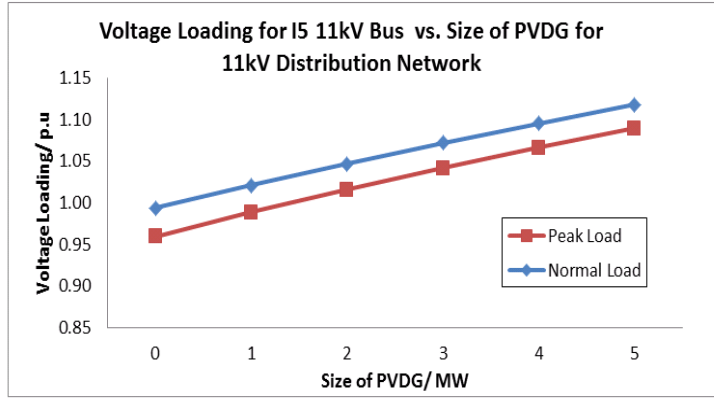

Figure 14. Voltage Loading for I5 $11 \mathrm{kv}$ Bus vs. Size of PVDG for $11 \mathrm{kV}$ Distribution Network

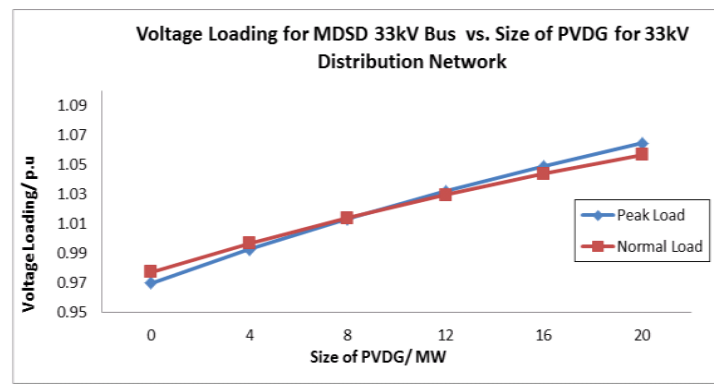

Figure 16. Voltage Loading for MDSD 33kV Bus vs. Size of PVDG for $33 \mathrm{kV}$ Distribution Network

\subsection{Impact of PVDG on Short-circuit Current}

With the presence of PVDG, the short circuit level for each bus increases for both cases as shown in Table 1 and Table 2.

Table 1. Three Phase Fault Current with and without PVDG for $11 \mathrm{kV}$ Distribution Network

\begin{tabular}{lrccc}
\hline BUS & $\begin{array}{c}\text { BUS VOLTAGE } \\
\text { (KV) }\end{array}$ & \multicolumn{3}{c}{ 3 PHASE FAULT CURRENT (kA) } \\
\cline { 3 - 6 } & & Without & With 2MW & With 3MW \\
\hline $\mathbf{1 3 2 k V}$ & 132 & PVDG & PVDG & PVDG \\
\hline $\mathbf{1 1 K V}$ & 11 & 49.137 & 20.171 & 20.183 \\
$\mathbf{I 5} \mathbf{1 1 K V}$ & 11 & 1.9267 & 49.514 & 49.577 \\
$\mathbf{I 5 ~ 0 . 4 3 3 K V}$ & 0.433 & 38.544 & 40.884 & 42.491 \\
\hline
\end{tabular}

Table 2. Three Phase Fault Current with and without PVDG for 33kV Distribution Network.

\begin{tabular}{lrccc}
\hline BUS & BUS VOLTAGE $(\mathbf{k V})$ & \multicolumn{3}{c}{ 3 PHASE FAULT CURRENT (kA) } \\
\cline { 3 - 5 } & & Without PVDG & With 11MW PVDG & With 16MW PVDG \\
\hline 132kV & 132 & 20.000 & 20.160 & 20.201 \\
33KV & 33 & 21.361 & 21.650 & 21.724 \\
MDSD 33KV & 33 & 2.2708 & 3.053 & 3.369 \\
MDSD 11KV & 11 & 5.631 & 8.382 & 9.650
\end{tabular}


It is compared with the network without installing PVDG and the results show an increase level of fault currents with respect the size of the PVDG installed. As the size of the PVDG increases, the faults level increases too. The cause of the increasing faults current is the synchronous generator for DG. This is because when short circuit happens on a system powered by generators, the generator will keep on producing voltage due to the maintained field excitation. The turbines or prime movers need to drive the generator at normal speed, hence, the generated voltage draws more fault current from the generator to the short-circuit. The protection scheme may need to change as it may influence reliability and safety of the system.

\section{CONCLUSION}

There are some significant factors which are location and size of PVDG that cause impacts on the distribution system. From detail analysis of PVDG location an size impacts on power losses, it shows a positive effect on the distribution system unless the sizing does not over the maximum penetration level. Besides, it also shows that suitable location needs to be determined in order to see for which location, PVDG will decrease the system's power losses to the minimum value. From investigation on impacts of PVDG on voltage profile, it shows that the introduction of PVDG may be good in improving voltage profile as it can provide a portion of active power to the load. However, over-sized PVDG can cause a negative impact on distribution system such as reverse power flow and over voltage. Besides, the installed PVDG into the distribution networks causes an increase in short-circuit current with the increase in the size of PVDG. Proper protection coordination for devices such as relays and circuit breakers need to be employed. In short, with the use of PVDG, it will benefit to the environment and to some of the aspects in power system. However, there are still some negative impacts that need further studies on. Hence, modeling, control and optimization of PVDG integration in grid system need to be researched on in order to obtain full benefit.

\section{ACKNOWLEDGEMENTS}

The authors would like to express gratitude to the Malaysian Ministry of Higher Education and Universiti Malaysia Pahang for the research grant (RDU150125) and laboratory facilities.

\section{REFERENCES}

[1] A. F. A. Kadir, T. Khatib, and W. Elmenreich, "Integrating photovoltaic systems in power system: Power quality impacts and optimal planning challenges," Int. J. Photoenergy, vol. 2014, 2014.

[2] S. N. Fadilah, N. M. Saad, M. F. Abas, and N. L. Ramli, "Modeling and simulation of UPFC for dynamic voltage control in power system using PSCAD/EMTDC software," ARPN J. Eng. Appl. Sci., vol. 10, no. 21, pp. 9943-9948, 2015.

[3] J. H. Tang, A. M. Busrah, A. K. M. Hussin, and M. Z. C. Wanik, "Power system study for Distributed Generation interconnection to distribution network- A Malaysian case study," 2014 IEEE Int. Conf. Power Energy, pp. $377-$ $381,2014$.

[4] S. Chyi, T. Hui, and W. Wei, "Feed-in tariff outlook in Malaysia," Renew. Sustain. Energy Rev., vol. 15, no. 1, pp. 705-712, 2015.

[5] S. Mekhilef, M. Barimani, A. Safari, and Z. Salam, "Malaysia's s renewable energy policies and programs with green aspects," Renew. Sustain. Energy Rev., vol. 40, pp. 497-504, 2014.

[6] S. L. Wong, N. Ngadi, T. Amran, T. Abdullah, and I. M. Inuwa, "Recent advances of feed-in tariff in Malaysia," Renew. Sustain. Energy Rev., vol. 41, pp. 42-52, 2015.

[7] S. Montoya-bueno, J. I. Muñoz, and J. Contreras, "A Stochastic Investment Model for Renewable Generation in Distribution Systems," IEEE Trans. Sustain. Energy, vol. 6, no. 4, pp. 1466-1474, 2015.

[8] L. J. Gray et al., "Solar influence on climate," Rev. Geophys., vol. 48, no. 2009, p. RG4001, 2010.

[9] V. Van Thong, J. Driesen, and R. Belmans, "Interconnection of distributed generators and their influences on power system," Int. Energy J., vol. 6, no. 1 PART 3, pp. 3127-3138, 2005.

[10] P. P. Barker and R. W. De Mello, "Determining the impact of distributed generation on power systems. Part I. Radial distribution systems,” Power Eng. Soc. Summer Meet. 2000. IEEE, vol. 3, pp. 1645-1656 vol. 3, 2000.

[11] M. M. Begovic, I. Kim, D. Novosel, J. R. Aguero, and A. Rohatgi, "Integration of Photovoltaic Distributed Generation in the Power Distribution Grid,” 2012 45th Hawaii Int. Conf. Syst. Sci., pp. 1977-1986, 2012.

[12] R. A. Shayani, M. Aurélio, G. De Oliveira, R. Sérgio, and C. Camargos, "Penetration Limit of Photovoltaic Distributed Generation - Case Study for the Italian Embassy in Brasília," in 2013 IEEE International Conference on Clean Electrical Power (ICCEP), 2013, pp. 665-672.

[13] V. A. Evangelopoulos, P. S. Georgilakis, and N. D. Hatziargyriou, "Optimal operation of smart distribution networks: A review of models, methods and future research,” Electr. Power Syst. Res., vol. 140, pp. 95-106, 2016.

[14] P. Prakash and D. K. Khatod, "Optimal sizing and siting techniques for distributed generation in distribution systems: A review," Renew. Sustain. Energy Rev., vol. 57, 2016.

[15] R. Ishak, A. Mohamed, A. N. Abdalla, and M. Z. Che Wanik, "Optimal placement and sizing of distributed generators based on a novel MPSI index," Int. J. Electr. Power Energy Syst., vol. 60, no. September, pp. 389-398, 
2014.

[16] A. J. G. Mena and J. A. M. García, "An efficient approach for the siting and sizing problem of distributed generation," Int. J. Electr. Power Energy Syst., vol. 69, pp. 167-172, 2015.

[17] S. Ganguly and D. Samajpati, "Distributed Generation Allocation on Radial Distribution Networks Under Uncertainties of Load and Generation Using Genetic Algorithm,” IEEE Trans. Sustain. Energy, vol. 6, no. 3, pp. 688-697, 2015.

[18] S. Y. Reddy, D. S. Reddy, and G. K. Rao, "Optimal siting and sizing of solar power sources in interconnection grid system,” J. Electr. Eng., vol. 16, no. 4, 2016.

[19] S. Nawaz, A. K. Bansal, and M. P. Sharma, "Power Loss Minimization in Radial Distribution Networks Using Reconfiguration and DGs," Indones. J. Electr. Eng. Comput. Sci., vol. 7, no. 3, pp. 583-592, 2017.

[20] M. Tajdinian and F. Shabaninia, "A new DG allocation approach based on biogeography-based optimization with considering fuzzy load uncertainty," IAES Int. J. Artif. Intell., vol. 4, no. 3, pp. 89-96, 2017.

[21] A. Kaviani-Arani, "Optimal Placement and Sizing of Distributed Generation Units Using Co-Evolutionary Particle Swarm Optimization Algorithms," TELKOMNIKA Indones. J. Electr. Eng., vol. 13, no. 2, pp. 247-256, 2015.

[22] M. A. Uqaili, A. A. Sahito, I. A. Halepoto, Z. A. Memon, and S. B. Dars, "Impact of distributed generation on network short circuit level," in Wireless Communications, Vehicular Technology, Information Theory and Aerospace \& Electronic Systems (VITAE), 2014 4th International Conference on, 2014, pp. 1-5.

\section{BIOGRAPHIES OF AUTHORS}

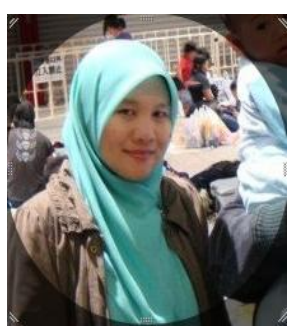

Norhafidzah Mohd Saad received her B. Eng (Hons) Electrical, Electronics \& System from Universiti Kebangsaan Malaysia (2002) and M. Sc. In Electrical Power Engineering (2006) from Universiti Putra Malaysia. She is currently a lecturer at Faculty of Electrical \& Electronics Engineering, Universiti Malaysia Pahang under Sustainable Energy \& Power Electronics Research Cluster. She is also a member of Board of Engineers Malaysia (BEM) and Institution of Engineers, Malaysia (IEM). Her research interest includes electrical power engineering, distributed generation, photovoltaics system and optimization in power and drive system.

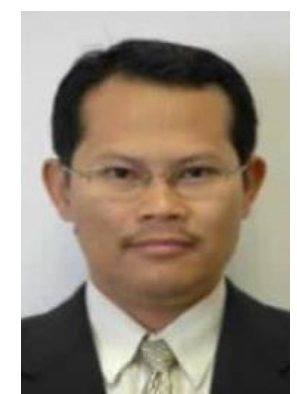

Muhamad Zahim Sujod received his B.Eng. (Hons.) Electrical and Electronics (2000) and M.Eng. Electrical and Electronics (2002) from Ehime University, Japan and Dr.-Ing. Electrical Power System from University of Duisburg-Essen, Germany (2014). He is currently a senior lecturer at Faculty of Electrical \& Electronics Engineering, Universiti Malaysia Pahang under Sustainable Energy \& Power Electronics Research Cluster. He is also a professional member of Board of Engineers Malaysia (BEM) and corporate member of Institution of Engineers, Malaysia (IEM). His expertise includes renewable energy, wind turbine system, photovoltaic system, energy conversion and electrical machine. 